\title{
Regulatory Compliance and Associated Quality of Amoxicillin in Drug Retail Outlets of Southwestern Ethiopia
}

\author{
Abdella Aman' \\ Gemmechu Hasen (iD) ${ }^{1,2}$ \\ Hayder Usman (iD) \\ Sultan Suleman ${ }^{1,2}$ \\ 'School of Pharmacy, Institute of Health, \\ Jimma University, Jimma, Oromia, \\ Ethiopia; ${ }^{2}$ Jimma University Laboratory \\ Drug Quality (JuLaDQ), Jimma, Oromia, \\ Ethiopia
}

Background: While the research findings confirm the existence of private drug retail outlets that do not comply with regulatory standards in many low-income countries, there are a lack of reports that evaluate the quality of medicines obtained from these firms. Therefore, the aim of this study was to evaluate the regulatory compliance of the retails and associated quality of amoxicillin in Southwestern Ethiopia.

Methodology: Forty-two drug retail outlets in Jimma town were evaluated using an inspection checklist developed by the Ethiopian regulatory authority, and dispensers from these retail outlets were interviewed using the pretested structured questionnaire. The drug outlets were coded and categorized into noncompliant and compliant drug retail outlets. The physicochemical quality of amoxicillin capsules obtained from these retail outlets were evaluated following methods described in the US Pharmacopoeia.

Results: The present study revealed that about $54.76 \%$ drug retail outlets were compliant with the regulatory standard. Factors like income of retail outlet, experience of dispenser, and training regarding good storage practice were associated with status of regulatory compliance ( $p$-value $<0.05$ ). The identification, dissolution, and assay results indicated that all amoxicillin samples obtained from both noncompliant and compliant drug retail outlets complied with pharmacopoeial specification limit. Besides, the independent unequal variance $t$-test revealed that there is no significant difference between mean dissolution and assay of API of the amoxicillin samples obtained these drug retail outlets ( $p$-value $>0.05$ ).

Conclusion: The regulatory compliance of private drug retail outlets in Jimma town is not satisfactory. Moreover, the laboratory findings revealed that all samples of amoxicillin capsules compiled with pharmacopoeial specifications acceptance for packaging and labeling information, identification, assay, and dissolution. However, despite the fact that assays of the amoxicillin from retail outlets are within the required specification, the assays of amoxicillin obtained from noncompliant retail outlets appears to be slightly degraded, which may potentially demonstrate the impact of noncompliance of the drug retail outlets on the quality of medicines. Keywords: drug retails, regulatory compliance, quality, amoxicillin, Ethiopia

\section{Introduction}

Ensuring the quality of medicines throughout their life cycle requires the effective monitoring of medicines at various levels from manufacturing to the end users to protect public health. ${ }^{1,2}$ As such, the World Health Organization (WHO) has established the regulatory standards for Good Pharmacy Practice that define the scope of practices, identifies who can practice, sets competency standards, and allocates resources to ensure their regulatory compliance. ${ }^{3,4}$ Thus, these regulatory
Correspondence: Gemmechu Hasen School of Pharmacy, Institute of Health Jimma University, PO Box 378, Jimma, Oromia, Ethiopia

Email gemmechuhasen2009@gmail.com; gemmechu.godena@ju.edu.et 
standards are crucial to monitor pharmaceutical firms, particularly the private drug retail outlets to ensure all pharmaceutical products on the market are safe, effective, and consistently meet approved quality standards. ${ }^{5,6}$ The private drug retail outlets are principal players in promoting access to medicines in low- and middle-income countries. $^{7,8}$ They have gained prominence in recent years with global initiatives, such as the affordable medicines facility for malaria (AMFM), exploring ways of utilizing them as a vehicle for expanding coverage for essential health services. ${ }^{9}$ The rising interest in drug retail outlets has resulted in increased frequency of interventions targeting their performance. Accordingly, the care-seekers reportedly choose the private drug retail outlets sector over the government health facilities because these drug retail outlets are more accessible, provide quicker service, and have more reliable drug stocks, are courteous and approachable, and in some cases are less costly. ${ }^{10}$ However, widespread regulatory infringement has been reported in private drug retail outlets, especially in developing countries. ${ }^{11-18}$ In these retail outlets, personnel requirements, structural design features for the premises, minimum equipment and material requirements, and provisions for good medicine storage and dispensing practices did not fully meet the regulatory standards of those countries. Conversely, while these findings confirm the existence of private drug retail outlets that do not comply with regulatory standards in many low-income countries, there are a lack of reports that evaluate the quality of medicines obtained from these retail outlets. From a recent report, amoxicillin capsules were highly affected by storage conditions, ${ }^{19}$ and the compliance assessment of the drug retail outlets to the regulatory standard was previously recommended in Ethiopia. ${ }^{20}$ Therefore, the quality of amoxicillin $500 \mathrm{mg}$ capsules was evaluated using methods mentioned in US Pharmacopeia after assessment of regulatory compliance of the drug retail outlets in Southwestern Ethiopia to decrease a risk of having poor quality amoxicillin in pharmaceutical retail outlets.

\section{Methodology}

\section{Study Design, Period and Location}

A facility based cross-sectional study design was employed among drug retail outlets in Jimma Town from March to April, 2020. Jimma town is located at $352 \mathrm{~km}$ from the capital, Addis Ababa. According to Central Statistical Agency (CSA) report the projected population of Jimma zone from 2014 to 2017 is estimated to be $2,986,957 .^{21} \mathrm{Jimma}$ is a relatively large town with nine legally operating wholesalers of pharmaceutical products which are currently supplying pharmaceutical products to drug retail outlets $(n=57)$, health centers $(n=4)$, clinics $(n=15)$ and hospitals $(n=2)$. Moreover, the experimental work was conducted in Jimma University Laboratory of Drug Quality (JuLaDQ).

\section{Equipments, Chemicals and Reagents}

The HPLC RP system (mode: LC; column: $4 \mathrm{~mm} \times$ $250 \mathrm{~mm}$; packing L1; detector: $230 \mathrm{~nm}$; flow rate: $1.5 \mathrm{~mL} / \mathrm{min}$; and injection volume: $10 \mu \mathrm{L}$, analytical balance, dissolution apparatus, UV spectrophotometer, $\mathrm{pH}$ meter, and thermometer were used. Monobasic potassium phosphate, acetonitrile HPLC grade, potassium hydroxide water HPLC grade, amoxicillin RS (secondary or working standard) and amoxicillin samples were used.

\section{Sample Collection and Procedure}

All private drug retail outlets were selected for observational study. Amoxicillin $500 \mathrm{mg}$ capsules were sampled using sampling strategy which is defined following the Medicine Quality Assessment Reporting Guidelines (MEDQUARG) as proposed by Newton et $\mathrm{al}^{22}$ based on the following question. Is there a difference in quality of medicines from among the different levels of drug retail outlets? Before experimental study was carried out, 42 drug outlets were evaluated using an inspection checklist developed by the Ethiopian regulatory authority, and dispensers from these retails were interviewed using the pretested structured questionnaire to assess the background of the dispensers and drug retail outlets. Based on the results from the observational study, the outlets were coded and categorized into noncompliant and compliant drug retail outlets based on the overall computed mean. Then, six drug retail outlets $(n=6)$ were selected from both noncompliant $(\mathrm{n}=3)$ and compliant drug retail outlets $(n=3)$ using convenience sampling method. The same brands of six samples of amoxicillin $500 \mathrm{mg}$ capsules were collected from each of the selected drug retail outlets. Finally, all samples were transported to Jimma University Laboratory of Drug Quality (JuLaDQ) on the same day of sample collection. For all samples, the visual and physical inspection for labeling and packaging was performed before physicochemical quality testing. After that, identity, dissolution test, and assay for the content of active ingredient of amoxicillin $500 \mathrm{mg}$ capsules were performed using the methods described in the US Pharmacopoeia. ${ }^{23}$ 


\section{Specific Test Method}

Physical Characteristics, Packaging and Labelling Information

Visual inspection of the physical characteristics of dosage form, packaging and labelling information was performed following the WHO checklist designed for health professionals to carry out visual inspection of medicines for signs of counterfeiting. ${ }^{24}$ As such, the capsules of all samples were checked for signs of moisture, dirty marks, embedded surface spots and presence of empty capsules.

\section{System Suitability}

System suitability test was performed routinely before sample analysis could commence according to the European Pharmacopoeia method. It is undertaken to verify resolution, column efficiency and repeatability of a chromatographic system to guarantee its competence for a particular analysis.

\section{Identification}

Identification tests were performed as per $\mathrm{USP}^{23}$ test method. The retention time of the major peak of the sample solution was checked for correspondence to that of the standard solution, as obtained in the assay.

\section{Assay of Amoxicillin}

Assay test of amoxicillin capsules was determined based method given in the US Pharmacopeia. ${ }^{23}$

\section{Buffer and Mobile Phase Preparation}

The buffer solution was prepared by dissolving $6.8 \mathrm{~g} / \mathrm{L}$ of monobasic potassium phosphate in water, and adjusted with $45 \%(\mathrm{w} / \mathrm{w})$ solution of potassium hydroxide to a $\mathrm{pH}$ of 5.0. Then, acetonitrile and buffer (1:24) were used for preparing mobile phase.

\section{Preparation Sample and Standard Solution}

The contents of NMT (not more than) 20 capsules were removed and completely mixed together. Then, the amount equivalent to $200 \mathrm{mg}$ of anhydrous amoxicillin was dissolved in a $200-\mathrm{mL}$ volumetric flask. The buffer was added to the volume, and sonicated as necessary to ensure the completion of the dissolution. Finally, $1.2 \mathrm{mg} / \mathrm{mL}$ of USP amoxicillin RS was prepared in buffer solution.

\section{Dissolution}

The dissolution test of amoxicillin capsules was determined based on the method given in the US Pharmacopeia. Dissolution apparatus II was set to 75 rotations per min (rpm) and temperature was maintained at $37^{\circ} \mathrm{C} \pm 0.5^{\circ} \mathrm{C}$ for a duration of $60 \mathrm{~min}$. The set volume of $900 \mathrm{~mL}$ of distilled water was used as a medium. The labelled amount of amoxicillin dissolved was compared with tolerances of the test according to USP which is not less than $80 \%(\mathrm{Q})$.

\section{Statistical Analysis}

Data was entered, cleaned, edited for any errors and analyzed by using Statistical Package for Social Science (SPSS) version 21.0 (IBM Corporation, Armonk, NY, USA). Descriptive statistics were computed. Graphs, tables, and numerical summary measures were used to display analysis of the results. Fisher's exact test was employed to determine nonrandom association between independent variables and outcome variables. Moreover, independent unequal variance $t$-test was used to determine significant difference between mean assays of amoxicillin samples, and mean drug release of amoxicillin sample at 60 min obtained from noncompliant and compliant drug retail outlets.

\section{Operational Definitions}

Noncompliant: drug retail outlets that possess a score less than the overall mean.

Compliant: drug retail outlets that possess a score greater than or equal to the overall mean.

Status of regulatory compliance is the position of drug retail outlets whether compliant or noncompliant retails.

\section{Results}

\section{Background of the Dispensers and Drug Retail Outlets}

Out of 57 drug retail outlets allowed to participate, 42 were evaluated and associated dispensers responded, with a response rate of $74 \%$. Among the studied retail outlets around $38 \%$ of them were owned by nonprofessional personnel. The results revealed that all retail outlets were licensed and the licenses were valid. Moreover, around $54 \%$ of drug retailers had service $>10$ years. Regarding the status of the dispenser working in the drug retail outlets only $7.1 \%$ were noncertified dispensers. Among study dispensers, the majority had experience of $<10$ years. Concerning training on the storage practice of drugs, the majority of dispensers $(57 \%)$ had no training related to drug storage practice (Table 1). 
Table I Background of the Dispensers and Drug Retail Outlets $(n=42)$

\begin{tabular}{|l|l|l|l|}
\hline \multicolumn{2}{|l|}{ Variables } & Frequency & Percentages \\
\hline Is a drug outlet licenced and valid? & Yes & 42 & 100 \\
& No & 0 & 0 \\
\hline Owner of the drug retail outlet & Professional dispenser & 26 & 61.9 \\
& Nonprofessional dispenser & 16 & 38.1 \\
\hline Service year of the drug retail outlets & $<10$ years & 19 & 45.2 \\
& $>10$ years & 23 & 54.8 \\
\hline Estimated income generation per month in Ethiopian birr & $<5000$ Ethiopian birr & 19 & 45.2 \\
\hline Status of the dispenser working in the drug retail outlets & $>5000$ Ethiopian birr & 23 & 54.8 \\
\hline Experience of dispenser & Certified dispenser & 39 & 92.9 \\
\hline Compliant regarding licensing requirements for drug retail outlets & Yoncertified dispenser & 3 & 7.1 \\
\hline Do you have training regarding good storage practice? & $<10$ years & 22 & 52.4 \\
\hline
\end{tabular}

\section{Evaluation of the Drug Retail Outlets for Regulatory Compliance}

The status of regulatory compliance of drug retail outlets according to the Ethiopian regulatory standard checklist out of $100 \%$ showed the overall mean of $51.46 \pm 10.981$ (Figure 1). Besides, the dichotomized level of compliance of drug retail outlets based on the overall mean revealed about $54.76 \%$ were compliant to regulatory standard (Figure 2).

\section{Factors Associated with Regulatory Compliance of Drug Retail Outlets}

Fisher's exact test revealed that types ownership, income per month of the drug retail outlets, experience of dispenser, and training regarding good storage practice were associated with status of regulatory compliance of drug retail outlets (Table 2).

\section{Physical Characteristics, Packaging and Labelling Information}

The physical characteristics, packaging, and labelling results showed that all the tested amoxicillin samples had no signs of moisture, dirty marks, embedded surface spots, or presence of empty capsules.
The packaging and labelling of all samples meets the minimum requirement required by the World Health Organization for packaging and labelling.

\section{Identification and Assay of the Amoxicillin}

The retention times of the major peaks in the chromatograms of all samples of amoxicillin capsules obtained were similar to that of the amoxicillin reference standard. The assay result of amoxicillin capsules for tested samples from compliant drug outlets ranged from $96.1 \%$ to $98.0 \%$ while samples obtained from noncompliant outlets ranged from $92.6 \%$ to $98.2 \%$. Moreover, all tested samples comply with Pharmacopoeia specification, and independent unequal variance $t$-test revealed no significant difference between mean assay of amoxicillin samples obtained from compliant and noncompliant drug retail outlets ( $p$-value $>0.05$ ) (Table 3 ).

\section{Dissolution}

The calibration curve revealed the presence of strong positive relationship $\left(\mathrm{R}^{2}=0.9954\right)$ between the concentration and absorbance over the RS amoxicillin concentration range of 444.44 to $666.66 \mu \mathrm{g} / \mathrm{mL}$ (Figure 3). Cumulative amoxicillin samples released at 60 min were determined from the calibration curve constructed by RS amoxicillin using UV-visible spectroscopic method. All tested samples comply with Pharmacopoeia specification, and independent unequal 


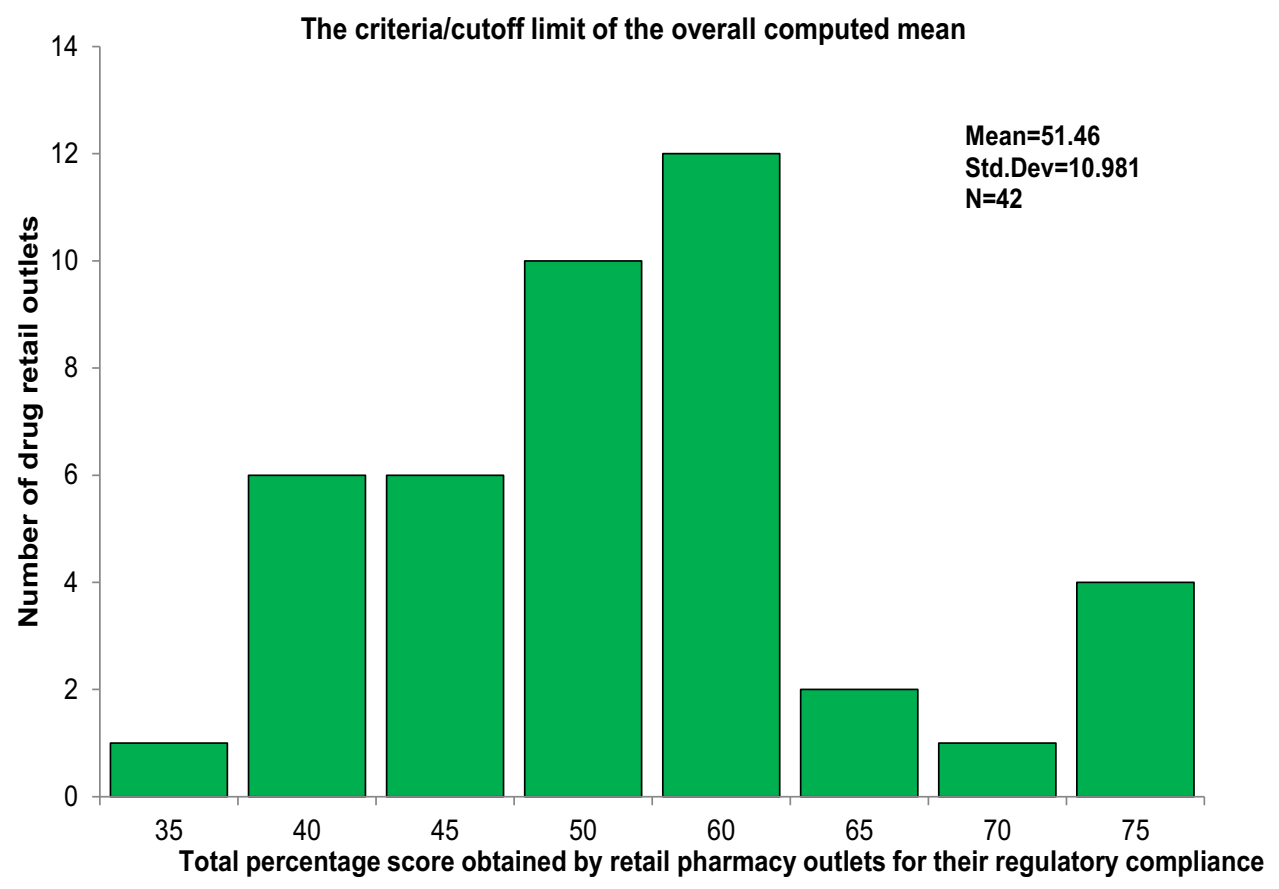

Figure I The criteria/cutoff limit of the overall computed mean.

\section{Status of regulatory compliance of drug retail outlets}

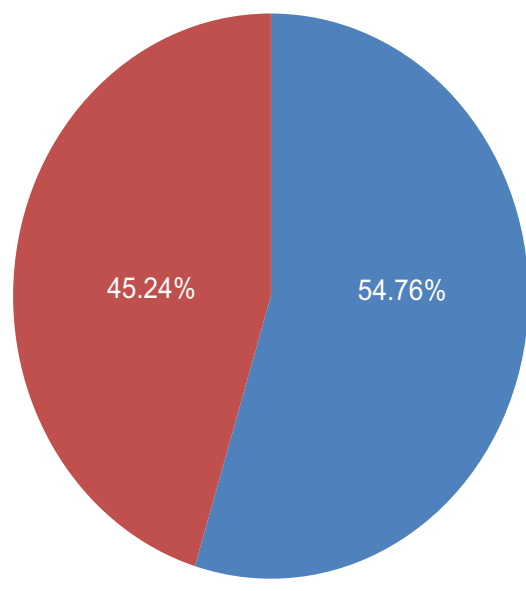

Figure 2 Status of regulatory compliance of drug retail outlets.

variance $t$-test revealed no significant difference between the mean of drug release samples at 60 min obtained from compliant and noncompliant drug retail outlets $(p$-value $>0.05)$ (Table 4).

\section{Discussion}

While research findings confirm the existence of the private drug retail outlets that do not comply with regulatory standards in many low-income countries, there are a lack of reports that evaluates the quality of medicines from these retailers. $^{11-18}$ Therefore, the quality amoxicillin
$500 \mathrm{mg}$ capsule samples were evaluated using the method mentioned in US Pharmacopeia after assessments of regulatory compliance of the drug retail outlets in Southwestern Ethiopia.

In this study, 42 private drug retail outlets of Jimma town were evaluated for regulatory compliance using the Ethiopian regulatory standard checklists. In addition, the quality of amoxicillin samples obtained from these retails were evaluated using methods described in the US Pharmacopeia. The present study revealed that about $54.76 \%$ of private drug retail outlets were compliant with the regulatory standard. Compared with studies conducted in Pakistan (19\%) ${ }^{25}$ and Tanzania (13\%), ${ }^{26}$ the current finding is higher regarding regulatory compliance of drug retail outlets. This difference may be related to variations of regulatory standards among given countries for licensing of retails and scope of methodologies that the authors employed to determine magnitude of compliance. The Fisher's exact test revealed that, types of ownership of the retail, income per month of the drug retail outlet, experience of dispenser, and training regarding good storage practice were associated with status of regulatory compliance of drug retail outlets. These imply that the professional dispenser, who owned the retail outlets, having more income per month, possessing adequate experiences and training regarding good storage practice may enhance regulatory compliance of private drug retails. Regarding quality of amoxicillin obtained from these retails, the physical characteristics of capsules, 
Table 2 Association Between Independent Variable and Outcome Variables

\begin{tabular}{|c|c|c|c|c|c|}
\hline \multicolumn{2}{|l|}{ Variables } & \multirow{3}{*}{$\begin{array}{l}\text { Frequency } \\
26 \\
16\end{array}$} & \multicolumn{2}{|c|}{$\begin{array}{l}\text { Compliance of Status of the } \\
\text { Drug Retail Outlets }\end{array}$} & \multirow{3}{*}{$\begin{array}{l}p \text {-value } \\
0.026^{*}\end{array}$} \\
\hline & & & \multirow{2}{*}{\begin{tabular}{|l} 
Compliant \\
18 \\
5
\end{tabular}} & \multirow{2}{*}{$\begin{array}{l}\text { Noncompliant } \\
8 \\
\text { II }\end{array}$} & \\
\hline Owner of the drug retail outlet & $\begin{array}{l}\text { Professional dispenser } \\
\text { Nonprofessional } \\
\text { dispenser }\end{array}$ & & & & \\
\hline Service year of the drug retail outlets & $\begin{array}{l}<10 \text { years } \\
>10 \text { years }\end{array}$ & $\begin{array}{l}22 \\
20\end{array}$ & $\begin{array}{l}14 \\
9\end{array}$ & $\begin{array}{l}8 \\
11\end{array}$ & 0.344 \\
\hline $\begin{array}{l}\text { Estimated income generation per month in Ethiopian } \\
\text { Birr }\end{array}$ & $\begin{array}{l}<5000 \text { Ethiopian birr } \\
>5000 \text { Ethiopian birr }\end{array}$ & $\begin{array}{l}19 \\
23\end{array}$ & $\begin{array}{l}14 \\
9\end{array}$ & $\begin{array}{l}5 \\
14\end{array}$ & $0.033^{*}$ \\
\hline Status of the dispenser working in the drug retail outlets & $\begin{array}{l}\text { Certified dispenser } \\
\text { Noncertified } \\
\text { dispenser }\end{array}$ & $\begin{array}{l}39 \\
3\end{array}$ & $\begin{array}{l}22 \\
1\end{array}$ & $\begin{array}{l}17 \\
2\end{array}$ & 0.581 \\
\hline Experience of dispenser & $\begin{array}{l}<10 \text { years } \\
>10 \text { years }\end{array}$ & $\begin{array}{l}22 \\
20\end{array}$ & $\begin{array}{l}16 \\
7\end{array}$ & $\begin{array}{l}6 \\
13\end{array}$ & $0.029 *$ \\
\hline $\begin{array}{l}\text { Compliant regarding licensing requirements for drug } \\
\text { retail outlets }\end{array}$ & $\begin{array}{l}\text { Yes } \\
\text { No }\end{array}$ & $\begin{array}{l}12 \\
20\end{array}$ & $\begin{array}{l}4 \\
19\end{array}$ & $\begin{array}{l}8 \\
11\end{array}$ & 0.098 \\
\hline Training regarding good storage practice? & $\begin{array}{l}\text { Yes } \\
\text { No }\end{array}$ & $\begin{array}{l}18 \\
24\end{array}$ & $\begin{array}{l}6 \\
17\end{array}$ & $\begin{array}{l}12 \\
7\end{array}$ & $0.028^{*}$ \\
\hline
\end{tabular}

Note: *Statistically significant at $p$-value $<0.05$

Table 3 Results of Quantity of API Capsules of Amoxicillin Samples $(n=20)$ from Drug Retail Outlets

\begin{tabular}{|c|c|c|c|c|c|c|}
\hline \multirow[t]{2}{*}{ Parameters } & \multicolumn{3}{|c|}{$\begin{array}{l}\text { Samples Obtained from Outlets that Complied } \\
\text { to Regulatory Requirements }\end{array}$} & \multicolumn{3}{|c|}{$\begin{array}{l}\text { Samples Obtained from Outlets Did Not Comply to } \\
\text { Regulatory Requirements }\end{array}$} \\
\hline & $\begin{array}{l}202 \mathrm{I}- \\
004- \\
00 \mathrm{I}-\mathrm{C}\end{array}$ & $2021-004-002-C$ & $2021-004-003-C$ & 202I-004-004-NC & 202I-004-005- NC & 202I-004-006- NC \\
\hline Assay I (\%lc) & 97.0 & 96.2 & 97.9 & 98.2 & 92.6 & 95.8 \\
\hline Assay 2 (\%lc) & 97.3 & 96.1 & 98.0 & 97.8 & 93.0 & 95.7 \\
\hline Mean (\%lc) & 97.2 & 96.1 & 97.9 & 98.0 & 92.8 & 95.7 \\
\hline \multicolumn{7}{|c|}{ Independent unequal variance $t$-test } \\
\hline Mean of SI & & \multicolumn{2}{|c|}{97.2} & \multicolumn{3}{|c|}{98.0} \\
\hline Mean of S2 & & \multicolumn{2}{|c|}{96.1} & \multicolumn{3}{|c|}{92.8} \\
\hline Mean of S3 & & \multicolumn{2}{|c|}{97.9} & \multicolumn{3}{|c|}{95.7} \\
\hline
\end{tabular}

Notes: $p$-value $>0.05$. In sample codes $\mathrm{C}$ and NC indicate that sample is obtained from compliant and noncompliant drug retail outlets respectively; SI, S2, S3 are sample I, sample 2, and sample 3, respectively.

packaging, and labeling information results obtained both from noncompliant and compliant retails revealed that all tested amoxicillin samples had no signs of moisture, dirty marks, embedded surface spots, and presence of empty capsules.

This indicates physical characteristics, packaging, and labeling of each $500 \mathrm{mg}$ amoxicillin capsule samples were in line with WHO guideline on packaging for pharmaceutical products. $^{24}$ Thus, the tested products may not have the stability problems associated with the packaging. ${ }^{27}$ The identification test result indicated that none of samples from retails had incorrect active pharmaceutical ingredients (APIs). This shows that there is no risk of treatment failure or death due to the investigated products. ${ }^{28}$ The assay result of APIs of the 


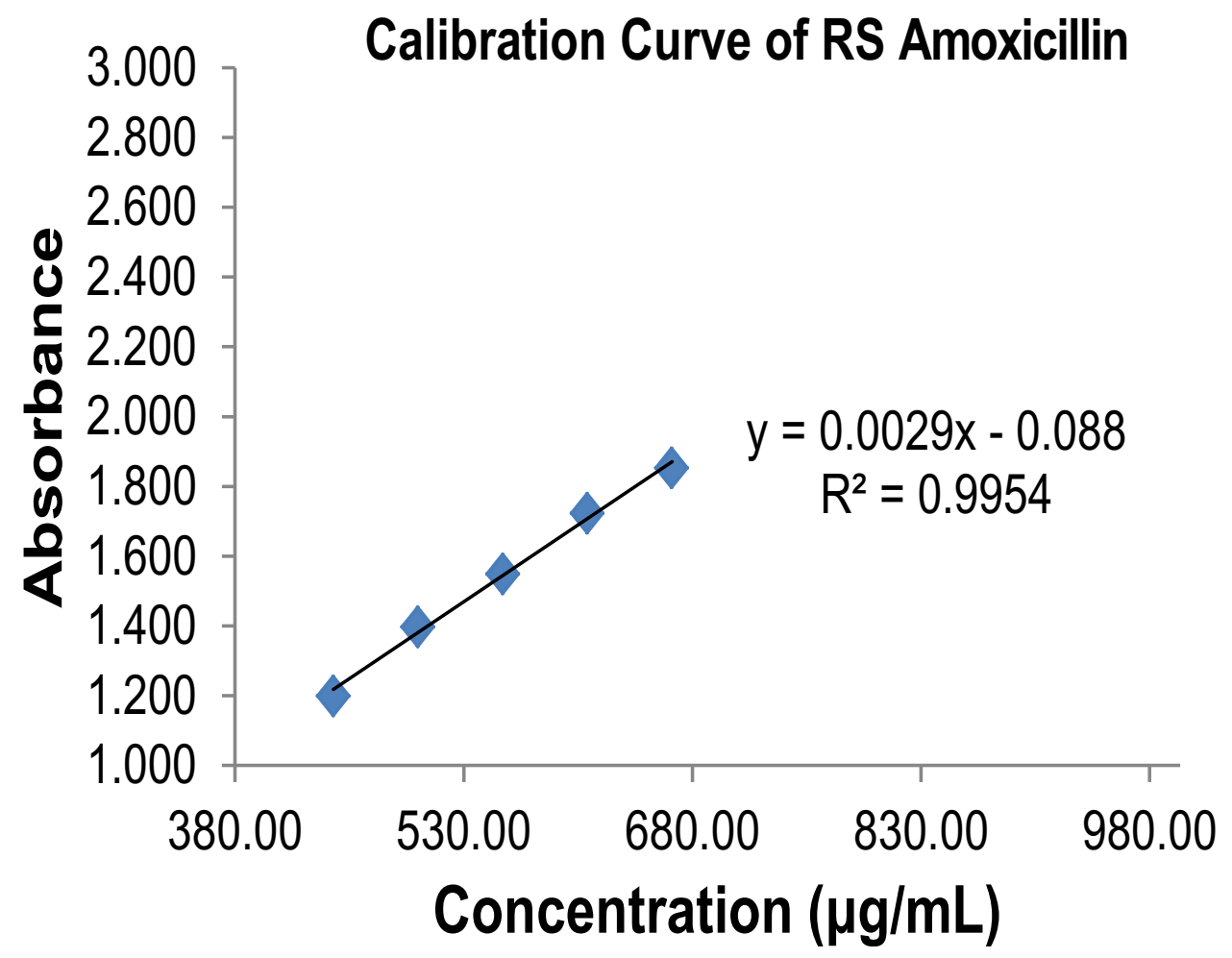

Figure 3 Calibration curve of amoxicillin reference standard in phosphate buffer at maximum wave length of $272 \mathrm{~nm}$.

amoxicillin capsule samples obtained both from noncompliant (92.6\% to $98 \%$ ) and compliant $(96.1 \%$ to $98.0 \%)$ retails complied with the Pharmacopoeia specification limit (\% $\mathrm{lc}=90-120 \%)^{23}$ The independent unequal variance $t$-test revealed that there is no significant difference between mean assay of API of the amoxicillin samples obtained from noncompliant and compliant retails ( $p$-value $>0.05$ ). Thus, the amount of APIs, the use of amoxicillin capsules obtained from noncompliant and compliant retails containing the same APIs may have similar clinical efficacy. However, the trend of variations of the assay results within and/or between noncompliant and compliant retails may potentially demonstrate the

Table 4 Cumulative Dissolution Data of Amoxicillin Release at 60 Minutes from the Samples Obtained from Selected Drug Retail Outlets Jimma, Ethiopia

\begin{tabular}{|c|c|c|c|c|c|c|}
\hline \multirow[t]{2}{*}{ Parameters } & \multicolumn{3}{|c|}{$\begin{array}{l}\text { Samples Obtained from Outlets that Complied } \\
\text { to Regulatory Requirements }\end{array}$} & \multicolumn{3}{|c|}{$\begin{array}{l}\text { Samples Obtained from Outlets Did Not Comply to } \\
\text { Regulatory Requirements }\end{array}$} \\
\hline & $\begin{array}{l}202 \mathrm{I}- \\
004- \\
00 \mathrm{I}-\mathrm{C}\end{array}$ & $2021-004-002-C$ & $2021-004-003-C$ & 202I-004-004-NC & $2021-004-005-N C$ & 2021-004-006- NC \\
\hline$\%$ DRI & 104.04 & 97.92 & 99.14 & 96.08 & 99.75 & 98.53 \\
\hline \%DR2 & 99.75 & 102.20 & 104.04 & 99.14 & 100.98 & 96.69 \\
\hline \%DR3 & 101.59 & 99.75 & 100.37 & 99.75 & 102.82 & 97.92 \\
\hline Mean & 101.80 & 99.96 & 101.18 & 98.32 & 101.18 & 97.71 \\
\hline \multicolumn{7}{|c|}{ Independent unequal variance $t$-test } \\
\hline \multicolumn{2}{|c|}{ Mean of \%DR of SI } & \multicolumn{2}{|c|}{101.80} & \multicolumn{3}{|c|}{98.32} \\
\hline \multicolumn{2}{|c|}{ Mean of \%DR of S2 } & \multicolumn{2}{|c|}{99.96} & \multicolumn{3}{|c|}{101.18} \\
\hline \multicolumn{2}{|c|}{ Mean of \%DR of S3 } & \multicolumn{2}{|c|}{101.18} & \multicolumn{3}{|c|}{97.71} \\
\hline
\end{tabular}

Notes: $p$-value $>0.05$. In sample codes $C$ and NC indicates that sample is obtained from compliant and noncompliant drug retail outlets respectively. DR of SI, DR of S2, DR of S3 are drug release of percentage sample I, sample 2, and sample 3, respectively. 
impact of noncompliance of the retails on the quality of medicines. This finding is in line with the reports that have been suggested as the improper storage of drugs could result in degradation of APIs which are expected in noncompliant retailers. ${ }^{19,29-31}$ According to US Pharmacopeia the labeled amount of amoxicillin capsules dissolved for $60 \mathrm{~min}$ should not be less than $80 \%$ (NLT $80 \%(\mathrm{Q})$ ). In this study, all tested samples compiled with Pharmacopoeia specification, and independent unequal variance $t$-test revealed no significant difference between mean of drug release samples at $60 \mathrm{~min}$ obtained from noncompliant and compliant retail outlets ( $p$-value $>0.05)$. This indicates that the use of Amoxicillin capsules obtained from noncompliant and compliant retails containing the same APIs may have similar bioavailability.

\section{Conclusions}

The regulatory compliance of private drug retail outlets in Jimma town is not satisfactory. Moreover, the laboratory findings revealed that all samples of amoxicillin capsules compiled with pharmacopoeial specification acceptance for packaging and labeling information, identification, assay, and dissolution. However, despite the fact that assays of the amoxicillin from both noncompliant and compliant retail outlets are within the required specification, the assays of amoxicillin obtained from noncompliant retailss appear to be slightly degraded which may potentially demonstrate the impact of noncompliance of the retails on the quality of medicines. Therefore, the investigators highly recommend the further research on comprehensive evaluation of many medicines to explore association between noncompliance and associated quality of medicines.

\section{Abbreviations}

APIs, active pharmaceutical ingredients; WHO, World Health Organization; RS, reference standard; USP, United State Pharmacopeia.

\section{Data Sharing Statement}

The documents supporting this study will be available upon request from corresponding author.

\section{Ethical Approval and Consent to Participate}

The Declaration of Helsinki was followed in undertaking this study. It was approved by the Institutional review board of Jimma University (Reference no. JHRPGD/921/20). A letter of permission was received from the office of Jimma Regional Health Bureau. The informed consent of the study participants was taken prior to interviews for collection of data and evaluation of drug outlets. The withdrawal right of study participants from involvement of study at any time was assured.

\section{Acknowledgments}

The authors would like to extend their heartfelt gratitude to all dispensers and owners of drug retail outlets of Jimma Town for accepting invitation to be involved in this study and permit evaluation of retails. We would also like to thank Jimma University Laboratory of Drug Quality for permitting the laboratory facilities.

\section{Author Contributions}

All authors made a significant contribution to the work reported, whether that is in the conception, study design, execution, acquisition of data, analysis and interpretation, or in all these areas; took part in drafting, revising or critically reviewing the article; gave final approval of the version to be published; have agreed on the journal to which the article has been submitted; and agree to be accountable for all aspects of the work.

\section{Disclosure}

The authors report no conflicts of interest in this work.

\section{References}

1. David L, Mohan J, Thomas L, et al. Ensuring the quality of medicines in resource-limited countries. An operational guide; 2007:11.

2. Suleman S, Woliyi A, Woldemichael K, et al. Pharmaceutical regulatory framework in Ethiopia: a critical evaluation of its legal basis and implementation. Ethiop $J$ Health Sci. 2016;26(3):259-276. doi:10.4314/ejhs.v26i3.9

3. World Health Organization. Assessment of medicines regulatory systems in sub-Saharan African countries; 2010:210.

4. International Pharmaceutical Federation (FIP) and WHO (World Health Organization). Joint FIP/WHO guidelines on good pharmacy practice; 2010:1-19.

5. Anello E A framework for good governance in the public pharmaceutical sector. Working draft for field testing and revision. Geneva: World Health Organization; 2007.

6. World Health Organization. The safety of medicines in public health programmes: pharmacovigilance an essential tool. WHO Libr Cat Data [Internet]; 2006. Available from: http://www.who.int/medicines/areas/qual ity_safety/safety_efficacy/Pharmacovigilance_B.pdf. Accessed November $18,2021$.

7. Poudel BK, Ishii I. Assessment of physical premises of selected pharmacies of Nepal. SAGE Open Med. 2016;4:1-4. doi:10.1177/ 2050312116654590

8. Wafula F, Abuya T, Amin A, Goodman C. The policy-practice gap: describing discordances between regulation on paper and real-life practices among specialized drug shops in Kenya. BMC Health Serv Res. 2014;14:1-11. doi:10.1186/1472-6963-14-394 
9. Ye Y, Arnold F, Noor A, et al. The Affordable Medicines Facility-malaria (AMFm): are remote areas benefiting from the intervention? Malar J. 2015;14(1):1-11. doi:10.1186/s12936-0150904-z

10. Uplekar M, Juvekar S, Morankar S, Rangan S, Nunn P. Tuberculosis patients and practitioners in private clinics in India. Int J Tuberc Lung Dis. 1998;2(4):324-329.

11. Goodman C, Kachur SP, Abdulla S, Bloland P, Mills A. Drug shop regulation and malaria treatment in Tanzania - why do shops break the rules, and does it matter? Heal Policy Plan. 2007;22:393-403.

12. Shrestha R, Ghale A. Study of good pharmacy practice in community pharmacy of three districts of Kathmandu valley, Nepal. Int $\mathrm{J}$ Sci Rep. 2018;4:240-245.

13. Shan SS, Naqvi BS, Fatima M, et al. Quality of drug stores: storage practices \& regulatory compliance in Karachi, Pakistan. Pak J Med. 2016;32(5):1071-1076.

14. Chejor P, Jamphel K, Tsheten Letho Z, et al. Compliance to current national medicines law for proper storage and dispensing of medicines at community pharmacies in Bhutan. Med Access Point Care. 2018;2:2399202618816900. doi:10.1177/2399202618816900

15. Suhail N, Ali SA, Qidwai W, et al. Storage of medicines and temperature control at community pharmacies in rural District of Sindh, Pakistan: an exploratory cross-sectional study. Middle East J Fam Med. 2016;14(4):17-27. doi:10.5742/MEWFM.2016.92843

16. Goel PK, Ross-Degnan D, McLaughlin TJ, Soumerai SB. Influence of location and staff knowledge on quality of retail pharmacy prescribing for childhood diarrhea in Kenya. Int $J$ Qual Health Care. 1996;8(6):519-526. doi:10.1093/intqhe/8.6.519

17. Khojah HMJ, Pallos H, Tsuboi H, Yoshida N, Abou-auda HS. Adherence of community pharmacies in Riyadh, Saudi Arabia, to optimal conditions for keeping and selling good-quality medicines. Pharmacol Pharm. 2013;2013:431-437.

18. Lenjisa JL, Mosisa B, Woldu MA, et al. Analysis of dispensing practices at community pharmacy settings in Ambo Town, West Shewa, Ethiopia. J Community Med Health Educ. 2015;5(1):16. doi:10.4172/2161-0711.1000329

19. Naidoo KK, Nompuku P, Mkalali SN, Shabangu V, Nkabinde L, Singh V. Post-marketing stability surveillance: amoxicillin. $S \mathrm{Afr}$ Fam Pract. 2006;48:14-14e. doi:10.1080/20786204.2006.10873401
20. Hasen G, Hussen H, Abduro F, et al. Knowledge, attitude and practice assessment of drug dispensers towards Drug products stability at drug outlets in Jimma Town: a crossectional. Indo Am J Pharm Res. 2020;10(05). doi:10.5281/zenodo.3864865

21. Federal Democratic Republic of Ethiopia. Population projection of Ethiopia for all regions at Wereda Level from 2014 - 2017. Addis Ababa: Central Statistical Agency; 2013.

22. Newton PN, Lee SJ, Goodman C, et al. Guidelines for field surveys of the quality of medicines: a proposal. PLoS Med. 2009;6:e100005. doi:10.1371/journal.pmed.1000052

23. The United States Pharmacopeial Convention USP. The United States pharmacopeial convention. Amoxicillin capsules. Revis Bull; 2018:0-3.

24. World Health Organization. Annex 9 guidelines on packaging for pharmaceutical. WHO Tech Rep Ser. 2002;902:120-153.

25. Butt ZA, Gilani AH, Nanan D, Sheikh AL, White F. Quality of pharmacies in Pakistan: a cross-sectional survey. Int J Qual Heal Care. 2005;17(4):307-313. doi:10.1093/intqhc/mzi049

26. Adikwu MU. Sales practices of patent medicine sellers in Nigeria. Health Policy Plan. 1996;11(2):202-205. doi:10.1093/heapol/ 11.2.202

27. Angeli DG, Trezza C. Quality and stability of ramipril generics/ copies versus reference ramipril (Tritace): a 3-month stability comparative study. Clin Drug Investig. 2009;29(10):667-676. doi:10.2165/11315270-000000000-00000

28. Alyami H, Dahmash E, Bowen J, Mohammed AR. An investigation into the effects of excipient particle size, blending techniques \& processing parameters on the homogeneity \& content uniformity of a blend containing low-dose model drug. PLoS One. 2017;12 (6):1-19. doi:10.1371/journal.pone.0178772

29. Brevedan MIV, Varillas MA, Vidal NLG. Pharmaceutical equivalence and stability of furosemide tablets in Argentina. Dissolution Technol. 2019;26(4):30-37. doi:10.14227/DT260419P30

30. Mansour O, Isbera M, Ismail G, Mayya G. The effect of temperature and moisture on the physical and chemical stability of furosemide tablets (40 mg) marketed in Syria. World J Pharm Res. 2018;7 (13):35-44.

31. Shafaat K. An overview: storage of pharmaceutical products. World J Pharm Pharm Sci. 2013;2:2499-2515.
Drug, Healthcare and Patient Safety

\section{Publish your work in this journal}

Drug, Healthcare and Patient Safety is an international, peer-reviewed open-access journal exploring patient safety issues in the healthcare continuum from diagnostic and screening interventions through to treatment, drug therapy and surgery. The journal is characterized by the rapid reporting of reviews, original research, clinical, epidemiological and post-marketing surveillance studies, risk management, health literacy and educational programs across all areas of healthcare delivery. The manuscript management system is completely online and includes a very quick and fair peer-review system. Visit http://www.dovepress.com/testimonials.php to read real quotes from published authors. 